\title{
DE LOS ESTADOS UNIDOS A MÉXICO Y PERÚ. PAUL FEJÖS Y PÁL KELEMEN, DOS HÚNGAROS BUSCANDO LAS HUELLAS DE LOS PUEBLOS PRECOLOMBINOS
}

\author{
KATALIN JANCSÓ
}

Universidad de Szeged

\begin{abstract}
Resumen: El director de cine, Paul Fejös (1897-1963), es conocido sobre todo por su carrera cinematográfica desarrollada en Hungría, Dinamarca, los Estados Unidos y otros países. Desde la segunda mitad de los años 30 del siglo XX, deja su carrera para dedicarse a sus investigaciones antropológicas y arqueológicas. De esta manera, llega a Perú donde hace un viaje de investigación explorando 18 sitios arqueológicos en la región de Machu Picchu y, posteriormente, estudia un pueblo amazónico, los yagua que viven en regiones fronterizas con Colombia y Brasil.

El arqueólogo e historiador del arte, Pál Kelemen (1894-1993), llega a los Estados Unidos en 1932 y empieza una larga carrera profesional durante la cual realiza varios estudios de viaje en diferentes países latinoamericanos, siendo autor de un considerable número de libros sobre el arte precolombino y colonial, reconocidos internacionalmente.

En mi ponencia, mi objetivo es estudiar las actividades antropológicas y arqueológicas de los dos investigadores, llevadas a cabo en el Perú (Paul Fejős) y en México (Pál Kelemen) durante la década de 1930.
\end{abstract}

Palabras clave: Paul Fejős, Pál Kelemen, arte precolombino, los yagua, Machu Picchu

\begin{abstract}
The film director, Paul Fejős (1897-1963), is best known for his film career developed in Hungary, Denmark, the United States and other countries. Since the second half of the 1930s, he left his career to devote himself to his anthropological and archaeological research. In this way, he arrived in Peru where he made a research trip exploring 18 archaeological sites in the Machu Picchu region and, later, studied an Amazonian tribe, the Yagua that live in regions near the Colombian and Brazilian borders. The archaeologist and art historian, Pál Kelemen (18941993) arrived in the United States in 1932 and began a long professional career during which he conducted several travel studies in different Latin American countries, being the author of a considerable number of books on the pre-Columbian and colonial art recognized internationally. In my paper, my objective is to study the anthropological and archaeological activities of the two researchers, carried out in Peru (Paul Fejős) and in Mexico (Pál Kelemen) during the 1930s.
\end{abstract}

Keywords: Paul Fejōs, Pál Kelemen, Pre-Columbian art, the Yagua, Machu Picchu

El presente trabajo, en cierto sentido, se vincula con una de mis actuales líneas de investigación: el estudio del indígena en obras de viajeros, fotógrafos y otros estudiosos húngaros que llegaron al subcontinente latinoamericano en la segunda par- 
De los Estados Unidos a México y Perú. Paul Fejős y Pál Kelemen, dos húngaros buscando las huellas de los pueblos precolombinos

te del siglo XIX y primera mitad del siglo XX. ${ }^{1}$ En el caso de Pál Kelemen y Paul Fejös, las personas estudiadas en este ensayo, hay un elemento común que hace su carrera aún más interesante: los dos emigraron a Estados Unidos y desde este país emprendieron sus viajes de investigación y exploración a América Latina. En los dos casos, aunque son conocidos por el público húngaro, se trata de investigadores destacados cuya obra latinoamericanista fue reconocida sobre todo por los círculos internacionales.

Tanto Kelemen como Fejös nacieron en Budapest, en 1894 y 1897, respectivamente. Pál Kelemen estudió historia del arte en Budapest, Munich y París (Bodrogi, 1978:356). Sus estudios fueron interrumpidos por la Primera Guerra Mundial, durante la cual sirvió como oficial de la Caballería Húngara durante cuatro años (AA, 27-10-2017). Paul Fejôs, que había recibido una educación jesuita, también interrumpió sus estudios (de medicina o química ${ }^{2}$ ) para servir en la Caballería Húngara durante la guerra (Luciak, 2016:305). A los dos húngaros les entusiasmaban diferentes ramas de artes: mientras a Kelemen le interesaban sobre todo el arte bizantino y el de la cristiandad temprana (Bodrogi, 1978:356), Fejős se interesaba por el teatro.

Después de la guerra, Kelemen volvió a sus estudios y, tras terminarlos, empezó a dirigir proyectos de investigación en el Museo de Bellas Artes de Budapest y otros museos de Europa (Viena, Londres, Florencia, Sevilla, Madrid) (Ortutay, 1979). A Kelemen le gustaba viajar, había emprendido sus primeros viajes a distintos países europeos con su educador durante sus años en la escuela secundaria. En 1930, durante un viaje realizado a Venecia para participar en un coloquio y una exposición, el joven historiador del arte conoció a una mujer norteamericana, Elisabeth Hutchings Zulauf, que vivía con sus padres en Italia donde estudiaba música clásica. Apenas un año después, la pareja se casó y decidieron hacer un viaje corto a Estados Unidos. En Nueva York y Boston, Kelemen visitó varios museos y bibliotecas y quedó impresionado por la profesionalidad y la amabilidad del personal de las instituciones y, al mismo tiempo, por la riqueza

\footnotetext{
${ }^{1}$ Esta investigación fue apoyada por el proyecto núm. EFOP-3.6.2-16-2017-00007, titulado Aspects on the development of intelligent, sustainable and inclusive society: social, technological, innovation networks in employment and digital economy. El proyecto ha sido apoyado por la Unión Europea y cofinanciado por el Fondo Social Europeo y el presupuesto estatal húngaro.

${ }^{2}$ Los estudiosos de Fejős no están de acuerdo sobre el tema: según algunos, Fejős nunca estudió medicina.
} 
y variedad de los objetos de arte precolombino expuestos. En una conversación con el director del Museo de la Universidad de Harvard, surgió la idea de redactar un resumen y análisis del arte de las civilizaciones mesoamericanas, sin embargo, no había expertos americanos que pudieran emprender tal tarea.

Seis meses más tarde, en abril de 1933, Kelemen y su mujer, Elisabeth, ya estaban preparados para realizar un viaje de varios meses a la península de Yucatán. Kelemen, que durante sus tempranos estudios en Hungría había tenido la posibilidad de ver y conocer excavaciones arqueológicas también, reconoció la necesidad de un examen multidisciplinario de estas culturas (Kelemen, 1981:8-10). La pareja llegó a la península en una época en la que el turismo todavía no había aparecido, y solo recién se habían iniciado las excavaciones en las distintas zonas arqueológicas en México. La exploración arqueológica del Templo de los Guerreros y de las Mil Columnas de Chichén Itzá estaba en progreso en el momento de la llegada de Pál y Elisabeth, que fueron cautivados por el arte maya, así como más tarde por el arte colonial. Elizabeth, abandonando su carrera de cantante de ópera, se convirtió en compañera exploradora de Pál en sus viajes de investigación a lo largo de las décadas siguientes, sería ella quien iría a documentar y fotografiar el trabajo de su marido (Kelemen - Kelemen, 2004). La pareja emprendió viajes por todo el subcontinente: reunió materiales en México, Guatemala, Honduras, El Salvador, Panamá, Nicaragua, Ecuador, Colombia, Perú y Bolivia (Ortutay, 1979). Encargado por la Biblioteca del Congreso de los Estados Unidos y la Galería Nacional del Arte, Kelemen hizo un trabajo pionero. Era historiador del arte con experiencias de investigaciones realizadas en Europa, por lo tanto, era imprescindible para él conocer la historia precolombina y colonial, tarea que pudo llevar a cabo en las bibliotecas norteamericanas. Reconoció que era más útil y cómodo trasladarse definitivamente a los Estados Unidos y emprender los viajes de investigación saliendo desde este país. En 1939, Kelemen obtuvo la ciudadanía estadounidense (Vasváry, K2:37).

En México, desde la revolución, se podía ver claramente la existencia de un nacionalismo en el que las culturas indígenas constituían un elemento de identidad nacional. Las primeras tres décadas del siglo se conocen en casi todo el subcontinente como la época del surgimiento de los precursores del indigenismo institucionalizado, vinculado en México con el gobierno de Lázaro Cárdenas (19341940). En 1917, se creó la Dirección de Estudios Arqueológicos y Etnográficos (a partir del año siguiente, Dirección de Antropología), cuyo director llegó a ser uno de los precursores del indigenismo institucional: Manuel Gamio. Esta y otras insti- 


\section{De los Estados Unidos a México y Perú. Paul Fejōs y Pál Kelemen, dos húngaros} buscando las huellas de los pueblos precolombinos

tuciones más creadas en estas décadas tendrían como objetivo más importante el fomento de las investigaciones arqueológicas, artísticas, antropológicas y etnográficas, la exploración de zonas arqueológicas, su conservación, restauración y estudio. El mismo Gamio propuso la idea de regionalizar el país en diez zonas culturales y dirigir investigaciones de la población indígena en estas áreas (SámanoRentería, 2004:143-145). Con el gobierno de Cárdenas, inicia un nuevo periodo en el cual el indigenismo sería elemento ideológico principal. Se creó el Departamento de Asuntos Indígenas y se apoyaron una serie de estudios antropológicos, arqueológicos e históricos (López Hernández, 2013:47-48). Por consiguiente, el proyecto de Kelemen no solo fue apoyado por los colegas norteamericanos sino que las circunstancias para llevar a cabo tal investigación también eran favorables en México y en una serie de otros países latinoamericanos.

Paul Fejős se encontraba en una situación semejante cuando llegó al Perú en 1939. En los años 20, durante el gobierno de Augusto B. Leguía, se creó el Patronato de la Raza Indígena, entre cuyos objetivos encontramos el estímulo a las investigaciones de las comunidades indígenas del país. Surgieron importantes pensadores en este periodo en el Perú también, por ejemplo Luis E. Valcárcel, historiador y antropólogo, investigador del Perú prehispánico que fundó el Instituto Indigenista Peruano en 1946 (Jancsó 2009:127-129). Los intelectuales de esta época empezaron a construir las bases de las futuras investigaciones científicas (Contreras Cueto, 2004:262). Después del fin del auge del caucho (1914), desde los años cuarenta, durante el gobierno de Manuel Prado, se podía percibir un interés creciente por los recursos de las zonas amazónicas del país, por lo que aumentó el número de estudios realizados en la región (Contreras - Cueto, 2004:284). Las investigaciones arqueológicas también se intensificaron: el trabajo de Max Uhle y Hiram Bingham -tras una caída en el interés por parte del gobierno después de 1915- proporcionaron un fuerte empuje a las posteriores exploraciones (Ramón Joffré, 2005:8-10). En estas circunstancias llegó Paul Fejōs a Lima con el objetivo de dirigir una expedición a la zona amazónica del Perú para estudiar un pueblo poco conocido: los yagua.

Fejős empezó a trabajar en la industria cinematográfica en 1919, durante la República de los Consejos ${ }^{3}$, como director escénico. Tras la derrota de la República, los directores de cine más reconocidos (Mihály Kertész y Sándor Korda) dejaron el

\footnotetext{
${ }^{3}$ La República Húngara de los Consejos fue proclamada por los grupos socialdemócratas y comunistas en Budapest, el 21 de marzo de 1919 y sobrevivió durante 133 días.
} 
país, lo que hizo posible que una persona tan joven como Fejős pudiera realizar proyectos cinematográficos. En 1919, Fejős obtuvo trabajo como decorador, pero un año más tarde ya fue director de cine. En medio año rodó cuatro películas, inspiradas en la libertad de las películas americanas. En 1921, ya se consideraba como el joven más talentoso de la industria cinematográfica húngara, quien, con poca financiación y mucho ingenio, pudo hacer películas mudas con mucho éxito (Balogh, 2004). Se sabe poco del interés de Fejős por la vida popular en este periodo temprano de su carrera, pero tenemos que mencionar que aun en Hungría, en 1922, dirigió un drama de pasión; asimismo, rodó dos películas de la cultura popular húngara en los años 30 (Tavaszi Zápor-Tormenta de Primavera- e Ítél a Balaton-Jugga el Lago Balaton-) (Fejös, 2004). Aunqe tenía orígenes aristocráticos, Fejős se sentía cercano a los empleados, trabajadores y campesinos y, sin duda, se vinculaba al movimiento de cultura popular y tradicional que surgió en aquella época en Hungría (Haudiquet, 1967:52).

La familia de Fejős (su padre murió cuando él tenía dos años) perdió gran parte de su fortuna invirtiendo en bonos de guerra (durante la Primera Guerra Mundial) (Luciak, 2016:305), por lo que Fejös se vio obligado a buscar un trabajo más remunerado. Este hecho y factores políticos también tuvieron influencia en su decisión: Fejős, que apenas hablaba inglés, dejó el país y migró primero a Viena y después a Estados Unidos en 1923 con tan solo unos cientos de dólares en el bolsillo. En los primeros meses, vivió en una pobreza aguda, no pudo encontrar trabajo alguno. Finalmente, encontró trabajo en el Instituto Rockefeller donde empezó a trabajar como asistente de laboratorio, pero, después de tres años, se mudó a California con la intención de buscar oportunidades en Hollywood. Gracias a un encuentro accidental, consiguió financiación (de cinco mil dólares) para la realización de su primera película americana titulada The Last Moment (1927). La película recibió críticas excelentes, incluso por el mismo Charlie Chaplin, y Fejös pronto se encontraba entre las celebridades de Hollywood con un contrato firmado con Universal Pictures y la oportunidad de hacer películas con un presupuesto de millones de dólares (Petrie, 2002:177-181). Fejôs quería dirigir películas que le gustaran y no quería satisfacer los gustos de los demás. Por lo tanto, harto de la brillantez de Hollywood, en 1931, dejó el lugar de sus sueños para volver a Europa, donde llegó a conocer a una persona que tendría una influencia decisiva en su carrera posterior (Antal, 1981:101). 


\section{De los Estados Unidos a México y Perú. Paul Fejōs y Pál Kelemen, dos húngaros buscando las huellas de los pueblos precolombinos}

En Europa, Fejôs comenzó a participar en proyectos de películas etnográficas en Dinamarca y Suecia. Participó en exploraciones y expediciones a Madagascar, las Islas Seychelles, las Filipinas, Siam (Tailandia) e India haciendo documentales. Su documental etnográfico más conocido se rodó en Siam, en 1937, con el título Un puñado de arroz (Sadoul, 1987:204). En 1937, un magnate industrial sueco, Axel Wenner-Gren invitó a Fejös a que le acompañara en una caza de tigres en Singapúr. Según la leyenda, Fejős le salvó la vida a Wenner-Gren, lo que significó el inicio de su amistad (Fejős, 2004). Wenner-Gren, en la segunda mitad de la década de los 30, creó fundaciones en Suecia y Estados Unidos para promover investigaciones científicas de medicina y antropología. En 1938, tras una correspondencia entre el magnate sueco y el embajador estadounidense en el Perú, le surgió a Wenner-Gren la idea de financiar una expedición a los Andes (Luciak, 2016:3010). Además, el magnate estaba interesado en los minerales del Perú, lo que también explicaba su afán de llegar a la región. Fejôs, invitado y apoyado por Wenner-Gren, viajó a Perú el 31 de diciembre de 1939 para llevar a cabo una investigación de campo en la región noreste del país, entre los ríos Putumayo y Amazonas. Sin embargo, durante su estadía en Cuzco, Fejös hizo investigaciones en la biblioteca de un monasterio franciscano donde encontró un libro sobre un fraile perdido en la selva y que hablaba de ciudades enterradas, historia que coincidía con los rumores de los locales sobre ciudades perdidas. Por consiguiente, cambiando de idea, Fejôs empezó su expedición en una región cercana a Machu Picchu en 1940 (Bidney, 2009:112), explorando una serie de sitios hasta entonces no conocidos. La expedición planeada originalmente se empezó solo en diciembre de 1940 (Luciak, 2016:3010). Durante esta segunda expedición antropológica, que duró casi un año, Fejös observó con su grupo de investigación el pueblo yagua, del que incluso rodó un documental (Yagua, 1941).

Tanto Kelemen como Fejós llegaron a unas tierras totalmente desconocidas, por lo tanto, su trabajo requería investigaciones previas. Los dos exploradores necesitaban leer libros de historia para poder apreciar y entender los restos de las culturas precolombinas encontradas. Se desprende de los textos de Kelemen que había leído varias crónicas españolas, especialmente sobre la conquista de México. Kelemen, en su libro Battlefield of the Gods (1937, publicado en húngaro en 1939) cita a varios cronistas, como Bernal Díaz del Castillo, Bernardino de Sahagún, las Cartas de Relación de Hernán Cortés, asimismo, hace alusión a las investigaciones y exploraciones realizadas por William H. Prescott y John Lloyd Stephens. Además, se desprende de su introducción que Kelemen podía contar 
Katalin Jancsó

con el apoyo de reconocidos expertos del Museo Peabody de Arqueología y Etnología de la Universidad de Harvard, la Dirección de Monumentos Prehispánicos de la Ciudad de México, el Museo Británico, el Museo Americano de Historia Natural, el Museo Nacional del Indio Americano, entre otros muchos (Kelemen, 1939:7-8). Paul Fejős también intentó reunir fuentes sobre las tierras exploradas, conocía las descripciones de Hiram Bingham sobre sus exploraciones realizadas entre 1911 y 1915, utilizó los Comentarios Reales de Garcilaso de la Vega y conocía la obra de José Toribio Medina, que por primera vez había publicado en 1895 la descripción del viaje de exploración de Francisco de Orellana a la Amazonía. En sus textos, Fejős también hace alusión al fraile checo Samuel Fritz, las obras de los científicos Antonio Raimondi, Charles Marie de la Condamine y de viajeros como el francés Paul Marcoy. En suma, los dos húngaros iniciaron su trabajo explorador e investigador bien preparados, con conocimientos científicos.

El primer libro escrito de Pál Kelemen del arte latinoamericano fue el ya mencionado Battlefield of the Gods. El género de este libro es difícil de definir, es una mezcla de literatura de viajes y un libro científico de historia e historia del arte. Kelemen habla así de sus objetivos en la introducción:

Fui a estudiar los restos del arte precolombino al valle de México y a la península de Yucatán con las lentes de un historiador del arte. Me encontraba sorprendido ante las construcciones mayas brillantes situadas a la altitud del nivel del mar en las selvas tropicales del Yucatán, asimismo, me impresionó el arte de los aztecas bárbaros desarrollado a 7600 pies sobre el nivel del mar. Pero, mientras me concentraba en las obras maestras de las culturas precolombinas, me vi obligado a conocer el arte maravilloso de la época colonial española y la propagación del cristianismo. Estaba tan cautivado por la riqueza artística ilimitada de esta tierra que hice bocetos y estudios que servirían de preparación para mi obra futura en la que quisiera estudiar exclusivamente el arte antiguo del globo occidental. No es tan fácil viajar en México como en las carreteras de Europa que son viables ya por las descripciones de los viajeros. [...] Cada uno puede descubrir su propio México. Es como el sabor y el olor de un vino exquisito: cuanto más lo tomamos, más nos atrae y más lo queremos [...] (Kelemen, 1939: s. p.). ${ }^{4}$

${ }^{4}$ Las traducciones fueron hechas por la autora del presente ensayo. 


\section{De los Estados Unidos a México y Perú. Paul Fejōs y Pál Kelemen, dos húngaros buscando las huellas de los pueblos precolombinos}

El libro refleja los pensamientos iniciales de su autor: Kelemen describe brevemente las condiciones del viaje y sus experiencias, al mismo tiempo que ofrece una sinopsis histórica sobre todo de la época de la conquista. Además de estudiar las circunstancias de la publicación de las obras de Bernal Díaz del Castillo y Hernán Cortés, se compromete a analizarlas y compararlas. En otro capítulo, hace lo mismo con las obras de los dos investigadores americanos, Prescott y Stephens, pioneros de los estudios de las culturas precolombinas. A Kelemen no solo le interesan las obras de arte sino que quiere conocer también la historia de estas culturas, la gente, sus costumbres. En su libro se mezclan las descripciones del viajero, las de un explorador y los textos de un historiador del arte. Proporciona al lector datos exactos de las construcciones precolombinas, su función, historia y las costumbres relacionadas con los edificios, concentrándose especialmente en las ruinas de Chichén Itzá y Uxmal, entre otras (Kelemen, 1939:42-54, 64-66). En sus descripciones de las riquezas de arte, además de detallar las obras encontradas en tierras mayas, aparecen obras y edificios de la época colonial en la Ciudad de México, Taxco, Toluca o Tlaxcala, ofreciendo un análisis científico de los estilos artísticos aplicados. Kelemen también escribe sobre el desarrollo de la historia de los pueblos mexicanos a lo largo de los siglos, además de hablar de sus experiencias de viaje y de las características de la gente que conoció.

Es interesante examinar su postura hacia el indígena. Su primer encuentro con los indígenas mayas ocurrió cuando desembarcaron en el puerto de Progreso en la península de Yucatán. "Allí estaban esos jóvenes pequeños de color rojomarrón, su expresión facial recordaba un poco a los malayos" - escribe Kelemen (Kelemen, 1939:30). Hablando de los mayas, destaca que entre todos los pueblos precolombinos, ellos tenían las más altas habilidades artísticas y talentos. Además, su resistencia a los ataques del hombre blanco era más fuerte que en otros lugares (Kelemen, 1939:31). En una de sus descripciones de ciudades, aprecia así los valores del indio maya:

El indio maya es un granjero cuidadoso, un trabajador bueno y persistente, un excelente albañil. Está satisfecho con poco, no es un amante de dinero, no está preocupado por su inseguridad. Su expresión facial es impasible, pero su atención y su ingeniosidad se refleja en su rostro (Kelemen, 1939:32).

Caracteriza su vestido como de "distinción inconsciente". En varias ocasiones utiliza atributos positivos, como fieles, trabajadores, atentos, hábiles artesanos, cercanos a la naturaleza. Kelemen dedica unos párrafos a la religión precolom- 
bina y la adaptación de las enseñanzas cristianas y su presencia en el alma india. Concluye su opinión sobre los efectos de la evangelización en una frase corta: "Pero el cristianismo llegó a ser realmente suyo cuando podían arrodillarse ante una cruz tallada por indios y cuando desde la cima de la cruz les miraba un Cristo Indígena como Redentor" (Kelemen, 1939:111). También hace notar en algunas partes la separación entre las capas indígena y mestiza en la sociedad. Muestra claramente este distanciamiento su estudio de los mestizos y los indígenas en la ciudad de Progreso: en su descripción, los indígenas mayas aparecen en un lado de la plaza mayor en su vestido tradicional bailando sus danzas acompañadas de música indígena, mientras, al otro lado de la plaza, en la zona de los pequeños negocios y restaurantes se reúnen los jóvenes blancos y mestizos. Los mestizos, según Kelemen,

son un pueblo orgulloso surgido de la mezcla de sangre española e indígena que constituyen un vínculo entre los mayas sencillos y la juventud dorada de las reposterías. Están vestidos a la última moda, sin embargo, desde las voces de la orquesta, hasta los pasos del baile, todo nos presenta un mundo lejano. Un mundo, donde los pasos alisios constantes balancean árboles de plátano y cocoteros (Kelemen, 1939:34).

Kelemen concluye su primer libro sobre México con una imagen que refleja perfectamente el encuentro de las dos culturas y la sobrevivencia de las culturas antiguas. Durante su último encuentro con indígenas y en los momentos de despedida, estalla una tormenta con truenos y relámpagos. Y, dice Kelemen, "como si los dioses quisieran declarar que todavía están vivos, la línea de un rayo en zigzag fulmina en el cielo encima del relicario" (Kelemen, 1939:168).

En sus obras posteriores $(1943,1951,1969)$, Kelemen ofreció una síntesis de sus extensos estudios sobre el arte latinoamericano de las épocas precolombina y colonial, de alto nivel profesional. El género de estas obras ya es más fácil de definir, son libros científicos, entre los cuales quisiera destacar el titulado Arte de las Américas (1969), que se publicó en húngaro también (1981). En este libro Kelemen hace un análisis exhaustivo de las diferentes ramas artísticas de las Américas precolombina y colonial, detallando en el prefacio de la edición inglesa las circunstancias de su acercamiento a Hispanoamérica y, en la versión húngara, otras experiencias de sus viajes. La edición húngara también cuenta con el resumen de su carrera redactada por László Borsányi, el antropólogo latinoamericanista húngaro. 


\section{De los Estados Unidos a México y Perú. Paul Fejōs y Pál Kelemen, dos húngaros}

buscando las huellas de los pueblos precolombinos

Paul Fejōs publicó dos libros sobre sus expediciones realizadas en el Perú, así como una serie de artículos en revistas científicas (1940, 1941abcde). En su informelibro de las exploraciones en la Cordillera Vilcabamba, Fejős describió detalladamente las circunstancias de la expedición. No viajó solo sino con un grupo de numerosos expertos, incluidos un geólogo, un lingüista (de la Universidad San Marcos de Lima), un zoólogo (del Museo de Historia Natural de Lima), un inspector del Patronato Arqueológico del Perú, fotógrafos, ingenieros y personal técnico, topógrafos, dibujantes. Además, tenían científicos visitantes de Stanford University y del Instituto de Estudios Andinos. El grupo de Fejös fue apoyado por otros expertos asesores, como el agregado de la Embajada de los Estados Unidos en Lima, profesores y el rector de la Universidad de Cuzco y el mismo Julio C. Tello, Director del Museo de Antropología en Lima. La expedición también fue apoyada por el gobierno peruano. Todos estos detalles demuestran la importancia de la expedición y el sumo interés nacional e internacional por sus resultados (Fejős, 1944:6). Fejős también explicó en la introducción que no había sido su intención originaria dirigir una expedición arqueológica y si hubieran sido conscientes de la magnitud del trabajo, no lo habrían empezado, puesto que la expedición no contaba con un arqueólogo, hecho que intentaron compensar con el trabajo documentario: un número excepcional de fotos (más de mil fotos fueron tomadas) y dibujos hechos en cada fase de la limpieza de los sitios encontrados. Fejös quería dejar claro que su intención era limpiar los sitios (con la ayuda de varios cientos de trabajadores) y prepararlos para posteriores investigaciones arqueológicas. De hecho, Julio C. Tello, empezó a trabajar ya en 1942 en la región (Fejős, 1944:5).

En el libro, Fejős se refirió constantemente a las exploraciones de Hiram Bingham, señalando en qué sitios había excavado Bingham y cuáles eran los sitios no conocidos anteriormente. El grupo hizo exploración en el valle de Urubamba, en las cordilleras de Vilcabamba, al sur del sitio de Machu Picchu. El investigador húngaro introdujo el informe con una descripción topográfica y climática y un estudio de las investigaciones anteriores realizadas en la zona (Fejôs, 1944:13-19). Fejős dio una detallada descripción de seis sitios grandes y otros cuatro más pequeños, proporcionando información sobre las terrazas, escaleras, baños, canales artificiales y sistemas de agua, depósitos, plataformas, puentes, grupos de edificios y caminos incas. En todos los casos, dio cuenta de tamaños exactos y del proceso de limpieza y el trabajo realizado. En algunos lugares, encontraron restos de cerámica o de semillas y, basándose en los hallazgos y en la forma de las construcciones, el grupo intentó hacer un informe preliminar sobre la posible función de unos edificios y 
algunas plazas. Según Fejôs, las ruinas de Intipata (Inti Pata en el libro) y Wiñay Wayna no eran conocidos ni entre los locales ni por exploradores anteriores, por lo tanto, fueron descubiertos por esta expedición. Estos dos sitios, además, se extendían en un área más grande que la de Machu Picchu y tenían un sistema de terrazas de una extensión más grande que el de la "Montaña Vieja". Algunos de los edificios encontrados (30 en total en Wiñay Wayna) estaban perfectamente conservados (Fejös, 1944:49-53). Cinco de los sitios encontrados fueron limpiados, documentados y mapeados, y, en el caso del sexto sitio (Wiñay Wayna) se realizaron exploraciones preliminares (Fejős, 1944:59-60).

Fejős y su grupo pasaron meses con los trabajos antes de volver a Cuzco, desde donde emprendieron su segunda expedición a la Amazonía peruana. Esta segunda expedición no tenía tantos miembros como la primera, pero también fue apoyada por el gobierno peruano, así como por la Sociedad Geográfica de Lima. Fejôs y su grupo llevaron a cabo trabajo de campo y dos colecciones etnográficas fueron donadas al Museo Nacional de Lima y al Museo Nacional del Indio Americano. Además, un número elevado de fotos en blanco y negro y en color fueron presentadas al Museo Nacional del Indio Americano y al Museo Peabody de la Universidad de Yale. Expertos de la Universidad de Yale y de la Universidad de Columbia apoyaron a Fejős como asesores (Fejős, 1943:5). En los primeros párrafos de su informe, Fejôs explicó las razones de elección del pueblo examinado. La razón más importante fue que se trataba de un pueblo menos conocido y que anteriormente no se habían realizado estudios sistemáticos de aquella cultura.

Los yagua, llamados así por los pueblos vecinos, estaban en contacto con la civilización occidental ya desde la época colonial. A lo largo del siglo XIX, el pueblo sufrió el impacto de los caucheros que habían llegado a la zona. Tras la caída de la era del caucho, los indígenas fueron explotados por extractores de madera y otros recursos de la selva, lo que causó la migración del pueblo (Chaparro, 2008: 118). Anteriormente cazadores y recolectores seminómadas, los yagua se convirtieron en agricultores que tenían comercio por trueque con pueblos vecinos. A partir de 1930, misioneros protestantes llegaron a la región cercana a Colombia. Durante un conflicto entre Perú y Colombia (1932-33), varios cientos de indígenas murieron a causa del sarampión, enfermedad que habían llevado las tropas peruanas al territorio. En los años siguientes, los grupos del pueblo se vieron de nuevo forzados a migrar a otras partes más sureñas de la Amazonia (Mayor Bodmer, 2009:268-270). En la época en que Fejős llegó a la región con su grupo 
De los Estados Unidos a México y Perú. Paul Fejős y Pál Kelemen, dos húngaros buscando las huellas de los pueblos precolombinos

de investigadores, unos cinco mil yaguas vivirían en la zona, aunque Fejős informa sobre unas mil personas.

Fejős da cuenta de los diferentes nombres del pueblo usados por otros pueblos vecinos (ellos se llamaban a sí mismos Nihamwo) y menciona que se confunden con los Peba, un pueblo pariente. En la zona de investigación, Fejôs y su grupo pudieron identificar 25-35 clanes, entre los cuales hubo 12 clanes con los que pudieron establecer contacto y que visitaron, teniendo su base en un pueblo específico del clan Hormiga (Fejős, 1943:15). Siguiendo su método anterior, Fejős empieza su informe con una descripción topográfica e histórica, mencionando los investigadores que anteriormente habían contactado con el pueblo. Para poder realizar el trabajo de campo y la recolección de datos, el grupo de expedición necesitaba informadores entre los cuales había soldados y comerciantes peruanos, hacenderos y miembros (cazadores, mujeres y jóvenes) de los clanes conocidos. Uno de los informadores más importantes fue el chamán del clan Hormiga (Fejős 1943:25). Este mismo clan fue el que colaboró con Fejős en la realización del documental que se rodó durante su estadía en el pueblo.

Fejős dividió su libro en dos secciones grandes: la de los capítulos vinculados con la cultura material y la de la cultura inmaterial. En los diferentes capítulos de la primera, Fejős da un informe sistemático de las viviendas, vestidos, alimentos, transporte y comunicación y los diferentes utensilios e instrumentos (de caza, pesca, cerámica, tejido, talla de madera, juguetes, instrumentos musicales). En la segunda, describe las diferentes fases del ciclo de la vida, rituales, las instituciones sociales (la importancia de la familia y la función de sus miembros, el clan, la guerra, la propiedad, los crímenes y los castigos), las costumbres sociales, las artes, la religión, los mitos y los elementos integrantes de la cultura. Fejős dedica el último capítulo al tema de la aculturación, la única parte en el texto en la que aparece su propia opinión del pueblo. Según él, los yagua han resistido todos los intentos de asimilación. Con las palabras de Fejős:

(Los yagua) Han demostrado una resistencia pasiva hacia la cultura de los hombres blancos que les proyectaron una imagen poco envidiable como la terquedad y la estupidez, unas caracterizaciones inmerecidas. En realidad, sus expresiones impasibles, su incapacidad para cooperar con los hombres blancos no son más que mecanismos de defensa que les han permitido soportar por generaciones la presencia indeseable de los misioneros, el ejército, los propietarios de las haciendas y de los comerciantes. Todo se me aclaró 
Katalin Jancsó

cuando, en una ocasión especial, unos viajeros blancos pararon en nuestro lugar en el Marañón cerca de Pevas y expresaron su interés en comprar cerbatana de los yagua. Los yagua estaban detenidos con una expresión impasible como si no hubieran oído nada o como si no hubieran entendido lo que querían. Más tarde, me dijeron que era mejor no entender nada en la presencia de extraños (Fejös, 1943:108).

A Fejős y su grupo les costó un mes entero poder establecer buenas relaciones con el clan visitado. Los pueblos que conocieron tenían contacto con la civilización, pero no aceptaban cualquier elemento de la otra cultura, estaban interesados en conocer solo aquellos objetos que les pudieran servir para algo. Por ejemplo, en general, rechazaban las armas de fuego porque su ruido asustaba a los animales. Por lo tanto, solo aceptaron de la expedición regalos que podían usar. Fejös estaba convencido de que no era la falta de inteligencia la razón por la cual los yagua hubieran rechazado la cultura occidental. Simplemente, les gustaba mantener sus costumbres. Otro factor que Fejős mencionó fue la falta de interés de los yagua por las novedades. Les gustaba ver objetos extraños y desconocidos, pero no les interesaba aprender cómo funcionaban, no les interesaban las explicaciones teoréticas. Según Fejős, una de las razones de su comportamiento fue su aislamiento, sin embargo, había algunos detalles que era difícil explicar (Fejős, 1943:109).

Algunas veces el trabajo que las comunidades indígenas hacían para hombres blancos proporcionaba una oportunidad para establecer contactos entre diferentes clanes e individuos. En principio, no tenían confianza uno en el otro, sin embargo, el trabajo común les ayudaba crear una red de contactos entre clanes. Debido a los contactos con misioneros, soldados o hacendados, los indígenas recibían nombres quechuas o españoles que no utilizaban en comunidad. Entre las últimas afirmaciones de Fejős, el autor mencionó que contrariamente a la opinión de viajeros y etnógrafos, los yagua no eran estúpidos o perezosos. Les caracterizó como gente respetable y orgullosa que no se consideraba inferior a ningún otro pueblo y que se diferenciaba de los indígenas de la sierra. Sin embargo, eran muy tímidos, no tenían confianza en los extraños y temían su magia del diablo. Fejös estaba convencido de que su aislamiento geográfico y voluntario les iba a ayudar a poder mantener su cultura por un periodo largo (Fejôs, 1943:110-111). El libro de Fejős tiene muchos méritos, entre ellos, los dibujos y fotos que servían de documentación. Otro elemento, fuera de las descripciones detalladas y sistematizadas, fue el apéndice que se añadió a la obra. En el primer apéndice ofreció una lista de artefactos con la explicación de su función y uso, mientras el segundo apéndice con- 
De los Estados Unidos a México y Perú. Paul Fejős y Pál Kelemen, dos húngaros buscando las huellas de los pueblos precolombinos

tenía la descripción del sistema fonético de la lengua de los yagua y un glosario de vocablos, por tanto, Fejôs hizo una obra etnográfica muy compleja que por décadas constituía la única obra básica para el estudio del pueblo.

Fejős, después de pasar casi dos años en el Perú, volvió a Nueva York. El éxito del proyecto peruano contribuyó a que la fundación de Wenner-Gren se dedicara a los estudios de antropología. Fejős, después de las expediciones, trabajó de profesor visitante de antropología en la Universidad de Stanford. WennerGren y Fejős se involucraron en unos asuntos políticos ${ }^{5}$, pero Fejös pudo continuar su carrera científica, además de en la Universidad de Stanford, fue profesor de antropología cultural incluso en la Universidad de Yale y en la Universidad de Columbia en los años cuarenta y cincuenta. Llegó a ser un experto reconocido y fue invitado a tener el cargo de director de investigación de Viking Fund (Petri, 2012). Entre sus colegas, Fejös fue considerado como un hombre de arte del renacimiento, interesado especialmente en la cultura considerada por él como el arte de vivir en la sociedad (Bidney, 2009:113). En cuanto a su actividad arqueológica recibió la siguiente valoración:

Hacia 1940 inicia sus investigaciones en el valle de Urubamba, hasta cierto punto, sus trabajos pasan desapercibidos, como la mayoría de los trabajos científicos. Pero el aporte de Fejös, con su libro Archaeological explorations in the Cordillera Vilcabamba, Southestern Peru (1944), marca uno de los hitos más importantes de la arqueología de la ceja de la selva. Recorre el área, estudia algunos de los yacimientos señalados por Bingham, descubre otros y deja una información más valiosa que la de aquel (Bonavia, 1981:150).

Por sus descubrimientos arqueológicos, Paul Fejős fue condecorado con la Orden del Sol por el gobierno peruano (Vasváry F1/ab:51). Pál Kelemen tuvo también una carrera posterior exitosa. Sus obras gozaban de gran éxito, se convirtieron en un éxito de ventas que tuvieron que ser reeditadas un sinnúmero de veces. Su libro sobre el arte medieval, por ejemplo, tuvo 35 ediciones entre 1943 y 1969. Este libro fue calificado en 1944 como el estudio más completo y penetrante de todos los tiempos por el New York Times Book Review (Vasváry,

\footnotetext{
${ }^{5}$ Fejős se casó con una mujer llamada Inga Arrad, supuestamente una agente alemana y Wenner-Gren fue acusado de actividades pro-nazis. Axel Wenner-Gren se vio obligado a pasar años en México antes de que pudiera volver a Estados Unidos pero Paul Fejős también fue observado por agentes norteamericanos por varios años.
} 
K2:57). Kelemen visitó los sitios arqueológicos más importantes de América Latina en los años posteriores, hizo viajes de investigación a Italia, Portugal y España y dio conferencias sobre el arte latinoamericano en distintos museos y universidades de Estados Unidos, Canadá y Europa (Bodrogi, 1978:356). Fue doctor honorario de la Universidad de Arizona y se le otorgó la Orden Nacional al Mérito de Ecuador. Como ya se ha mencionado, el primer libro de Kelemen fue publicado antes de la Segunda Guerra Mundial, sin embargo, después del término de la guerra, durante los años del sistema socialista, su figura y sus obras pertenecían a la categoría de no deseables o prohibidas (Szente-Varga, 2017:52). Mientras Kelemen era un conferenciante e investigador popular en los centros educativos y las galerías de arte norteamericanos, su nombre se olvidó en Hungría. El único libro suyo que se publicó durante el socialismo, mucho más tarde de su publicación en inglés, fue el titulado Arte de las Américas, que hasta hoy es la obra más completa disponible en húngaro sobre el tema. El nombre de Fejōs permaneció más en el dominio público, aunque a los críticos y estudiosos que se ocuparon de su obra les interesaron casi exclusivamente su carrera en Hollywood y sus actividades en Europa (Vasváry, F1/ab:53, 54, 57, 58). Sus estudios y libros de antropología y arqueología no fueron traducidos al húngaro. Muy pocos autores hicieron mención de los detalles de sus trabajos antropológicos, y sus dos expediciones realizadas en el Valle de Urubamba y la Amazonía peruana son casi desconocidas para el público húngaro.

\section{Bibliografía}

Antal, István. 1981. "Egy magyar-amerikai karrier története. John W. Dods könyve Fejős Pálról” Filmkultuira, 81/1. 101-102.

Balogh, Gyöngyi. 2004. "Budapest évek (Fejős Pál magyarországi pályakezdése)" Filmspirál, 10. 33/2.

Bidney, David. 2009. "Paul Fejős 1897-1963" American Anthropologist, 66/1. 110115.

Bodrogi, Tibor (ed.). 1978. Messzi népek magyar kutatói. Az egyetemes néprajz magyar elófutárai és múvelóí. Budapest: Gondolat.

Bonavia, Duccio. 1981. "Tello y la Arqueología de la ceja de la selva" Historica, V/2.149-158. 
De los Estados Unidos a México y Perú. Paul Fejős y Pál Kelemen, dos húngaros buscando las huellas de los pueblos precolombinos

Chaparro Ortiz de Zevallos, Anahi. 2008. "Los yagua en el contexto del turismo étnico. La construcción de la cultura para el consumo en el caso de Nuevo Perú" Anthropologica, 26/26. 113-142.

Contreras, Carlos - Cueto, Marcos. 2004. Historia del Perú contemporáneo. Lima: IEP Ediciones.

Contreras, Carlos - Cueto, Marcos. 2008. "Caminos, ciencia y Estado en el Perú, 1850-1930" História, Ciências, Saúde-Manguinhos, 15(3), 635-655. Fecha de consulta: 11 de octubre de 2017. Asequible en: https://dx.doi.org/10.1590/ S0104-59702008000300005.

Fejős, Paul. 1940. "Proyecto para la investigación etnográfica de las tribus amazónicas" Boletín del Museo de Historia Natural "Javier Prado", IV/4/ 15. 534-543.

Fejös, Paul. 1941a. "Descubrimiento de las nuevas ciudades en la zona Cedrobamba" Revista del Instituto Arqueológico, V/8-9. 95-110.

Fejōs, Paul. 1941b. "Descubrimientos arqueológicos en el Perú: informe sobre los trabajos realizados en Cedrobamba (departamento del Cuzco) por la misión Wenner-Gren” Revista del Museo Nacional, 10/1. 91.

Fejős, Paul. 1941c. "La región del río Colorado" Boletín de la Sociedad Geográfica de Lima, LVIII/3. 221-242.

Fejös, Paul. 1941d. "Las ruinas Wenner-Gren" Boletín del Museo de Historia Natural "Javier Prado", V/16. 109-126.

Fejōs, Paul. 1941. "Nuevos descubrimientos arqueológicos en la región de Machu-Picchu" Chaski. Órgano de la Asociación Permana de Arqueologia, 1/3. 19-44.

Fejös, Paul. 1943. Ethnography of the Yagua. Viking Fund Publications in Anthropology. 1. New York: Viking Fund.

Fejös, Paul. 1944. Archaeological explorations in the Cordillera Vilcabamba. Viking Fund Publications in Anthropology. 3. New York: Viking Fund.

Fejōs, Zoltán. 2004. “A mûvészet és a tudományos érdeklődés határán. A népi tematika Fejős Pál életmúvében” Filmspirál, 10. 33/2.

Haudiquet, Philippe. 1967. "Fejôs Pál” Filmkultura, 67/6. 49-53.

Jancsó, Katalin. 2009. Indigenismo politico temprano en el Perú y la Asociación PróIndígena, Szeged.

Kelemen, Pál. 1939. Istenek csatatere. Budapest: Franklin. 
Kelemen, Pál. 1981. Régi amerikai múvészet. Ösi indián és spanyol gyarmati kor. Budapest: Corvina.

Kelemen, Pál - Kelemen, Elisabeth. 2004. Kelemen Journals. Incidents of Discovery of Art in the Americas, 1932-1964. San Diego: Sunbelt Publications.

Kelemen, Pál. 1937. Battlefields of the Gods: Aspects of Mexican History, Art, and Exploration. George London: Allen \& Unwin.

Kelemen, Pál. 1943. Medieval American Art: Masterpieces of the New World before Columbus. New York: Macmillan.

Kelemen, Pál. 1969. Art of the Americas, ancient and Hispanic, with a comparative chapter on the Philippines. New York: Crowell.

Kelemen, Pál. 1951. Baroque and Rococo in Latin America. New York: Macmillan.

López Hernández, Haydeé. 2013. "De la gloria prehispánica al socialismo: Las políticas indigenistas del Cardenismo" Cuicuilco, 20 (57), 47-74. Fecha de consulta: 29 de octubre de 2017. Asequible en: http://www.scielo.org.mx/scielo. php?script $=$ sci_arttext\&pid=S0185-16592013000200003\&lng=es\&tlng=es.

Luciak, Ilja A. 2016. "Vision and Reality. Axel Wenner-Gren, Paul Fejos, and the Origins of Wenner-Gren Foundation for Anthropological Research" Current Anthropology, 57. Supplement 14. 302-332.

Mayor Aparicio, Pedro - Bodmer, Richard E. 2009. Pueblos indigenas de la Amazonia peruana. Iquitos: CETA.

Ortutay, Gyula (ed.). 1979. Magyar néprajæi lexikon, Budapest: Akadémiai Kiadó. Versión electrónica: https://www.arcanum.hu/en/online-kiadvanyok/Lexikonokmagyar-neprajzi-lexikon-71DCC/

Petrie, Graham. 2002. Hollywood Destinies: European Directors in America, 1922 1931. Wayne State University Press.

Petri, Graham. 2012. "The travels of Paul Fejos" The Criterion Collection, August 31, 2012. Fecha de consulta: 05 de noviembre de 2017. Asequible en: www.criterion.com.

Ramón Joffré, Gabriel. 2005. "Periodificación en Arqueología peruana: geología y aporía". Bulletin de l'Institut français d'etudes andines, 34 (1). 5-33.

Sadoul, Georges. 1987. Historia del cine mundial: desde los orígenes. Siglo XXI.

Sámano-Rentería, Miguel Ángel. 2004. "El indigenismo institucionalizado en México (1936-2000): un análisis" Ordóñez-Cifuentes, José Emilio (ed.). La 
De los Estados Unidos a México y Perú. Paul Fejős y Pál Kelemen, dos húngaros buscando las huellas de los pueblos precolombinos

construcción del Estado nacional: democracia, justicia, paz y Estado de derecho. México: Universidad Nacional Autónoma de México. 141-158.

Szente-Varga, Mónika. 2017. El baúl de las nomeolvides. Relaciones búngaro-mexicanas. Budapest: Dialóg Campus.

\section{Archivos}

Arizona Archives Online

- Pál Kelemen Papers, 1914-1986, Bibliographical note

Colección Vasváry de la Biblioteca Somogyi de Szeged

- K2:37

- K2:57

- F1/ab:51

- F1/ab:53

- F1/ab:54

- F1/ab:57

- F1/ab:58

\section{Documentales}

Paul Fejős. 1941. Yagua

Paul Fejős. 1938. En handfull ris 